\title{
Estimating Component Yield for CLT Production
}

\author{
U. Buehlmann ${ }^{1}$ and R. E. Thomas ${ }^{2}$ \\ ${ }^{1}$ Department of Sustainable Biomaterials, Virginia Tech, Blacksburg, VA USA \\ ${ }^{2}$ USDA Forest Service, Northern Research Station, Princeton, WV USA \\ '(buehlmann@gmail.com), ${ }^{2}$ (ethomas@fs.fed.us)
}

\begin{abstract}
The emergence of cross-laminated timber (CLT) for building construction in North America may provide an additional and possibly more valuable product market for hardwood logs. Using the RaySaw sawing and ROMI rough mill simulators and a digital databank of laser-scanned low-grade yellow-poplar (Liriodendron tulipifera) logs, we examine the yield-recovery potential for components used in the production of CLT. Results include a sawing yield of $65 \%$ and a rough-mill yield of $78 \%$, for a total material yield of approximately $50 \%$. This study confirmed the usability of yellow poplar as a material for the production of CLT and allows to estimate the impact on our forest resource of increased use of yellow poplar CLT.
\end{abstract}

Keywords - Simulation, laser scan, log sawing, lumber sawing, yield, cross-laminated timber (CLT).

\section{INTRODUCTION}

Cross Laminated Timber (CLT) refers to largescale, solid wood panels with windows and supply line openings pre cut using $\mathrm{CNC}$ equipment in the manufacturing plant. These prefabricated panels leave the manufacturing plant on trucks ready to be installed at the construction site [1]. Indications exist that CLT may be a cost competitive construction method compared with concrete or steel, especially when all costs of erecting a building are accounted for [2] [3].

Over the past couple of years, numerous tall buildings have been erected using CLT. Examples include the Stadthaus in London, the Forte in Melbourne, the Wood Innovation Design Center in BC, Canada, the Treet block of flats in Bergen, Norway and the Brooks Commons Phase 1 building in Vancouver. The market potential for CLT in North America is estimated at 2.1 6.4 million $\mathrm{m}^{3}$ annually, e.g., two to six times today's annual production worldwide [4] [5].

At present, CLT structures are predominantly made using softwoods, however, applications involving hardwoods are growing. Hasslacher, a forest products company in Austria, built a single-family home in St. Magdalena, Austria with CLT made from birch. Today, Hasslacher's material is commercially available with certification according to EN $1995 \quad 1 \quad 1 \quad$ [6]. The American Hardwood Export Council (AHEC) has promoted CLT made from yellow-poplar (Liriodendron tulipifera), because it is abundant, inexpensive, and is strong [7]. Thus, while research about hardwood CLT is scarce, results confirm that it is suitable for use and that the production of hardwood CLT is technically feasible [8] [9] [10].

Hardwood CLT thus has the potential to become a competitive building material, thereby using hardwoods from US forests generating economic opportunities in rural regions. However, at the current time, little understanding exists as to the implications of the impact, positive or negative, on forest health, landowner finances, and rural economies from a potential increased use of hardwoods to manufacture CLT. This study investigated the production of CLT using hardwoods by simulating the cut-up of logs and timbers for CLT components, thereby estimating the yield recovery potential of hardwood CLT.

\section{RESEARCH METHODS}

Banks [11] defines simulation as the imitation of a real process over time. The forest products industry employs simulation to find optimum or sub-optimum solutions for the cut-up of their raw material. Typically, solid wood components are cut in a two-step process. The $\log$ is first cut into timbers (often referred to as lumber in industry parlance); the timbers then are cut into components after drying. To simulate these realworld processes, this study employed heuristic, iterative, optimum or sub-optimum search algorithms to obtain the overall highest value from the material processed. Although there is no time component involved, the industry still refers to these algorithms as simulation or as simulation optimization [11].

Simulation was used to investigate the potential yield of usable components from logs digitized using the US Forest Service high-resolution laser scanner [12], which then were sawn to timbers using the RaySaw sawing simulator [13]. The resulting timbers were thereafter cut to CLT components using the ROMI simulator [14].

\section{A. $\log s$}

Twenty-two medium quality yellow-poplar logs were randomly selected from two sites in the Central Appalachian region of the United States. These logs were graded to US Forest Service log grades to establish quality and market value [15]. Under Forest Service log grading rules, the best saw log grade is Factory 1, followed by Factory 2, and the lowest grade commonly sawn in mills in the United States is Factory 3. The logs 
used in this study were all Factory 2 grade logs. Table 1 lists the diameter, length, market value, whole log volume, sawn green volume, number of boards produced, and the kiln dried planed volume of the boards (timbers). Market value was determined by using an average of prices mills are paying for logs at the time of publication.

\section{B. High-resolution laser scanner}

The yellow-poplar logs (Table 1) were imaged using a US Forest Service high-resolution laser scanner system [12]. This scanning system enables determination of accurate shape and volume measurements to create a complete digital representation of a $\log$. A rendering of $\log$ number 12 in 3D is shown in Figure 1.

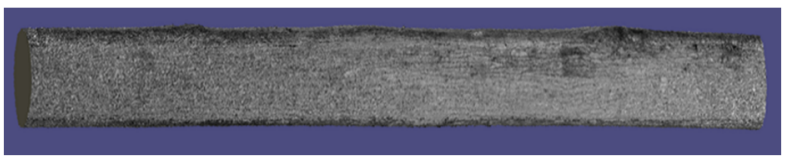

Fig. 1. High-resolution scan of yellow-poplar log 12 .

\section{Sawing simulator}

The laser-scanned logs (Table 1) were then virtually sawn into timbers using the RaySaw sawing simulator [13]. RaySaw was configured to simulate a band sawmill operating with a $5 \mathrm{~mm}$ thick saw kerf. Defect types, sizes, and locations on the timbers were predicted using modeled relationships among external defect indicators and internal features [16]. The target thickness of the dried and surfaced CLT lamination layers was set to $34 \mathrm{~mm}$, following the European Standard FprEN 16351 [17]. A drying allowance was added to the green timber sawing thickness to allow for drying shrinkage. To determine the target green thickness of the timbers cut, a green allowance based on a yellow-poplar tangential shrinkage factor of $8.2 \%$ (i.e., $4 \mathrm{~mm}$ ) was added [18]. Using the tangential shrinkage factor provides a maximum drying loss and provides a conservative estimate of recovery. Also, a surfacing allowance of $6 \mathrm{~mm}$ and a sawing variation allowance of $1 \mathrm{~mm}$ were added to the final target thickness. Thus, RaySaw [13] was configured to saw rough timbers of 45 $\mathrm{mm}$ thickness. Figure 2 shows an end view of $\log$ number 12, including defect locations with a typical sawing pattern used in this study. The sawing pattern found by RaySaw sawing simulator [13] maximizes the width of the timbers that results from the clear face of the $\log$.

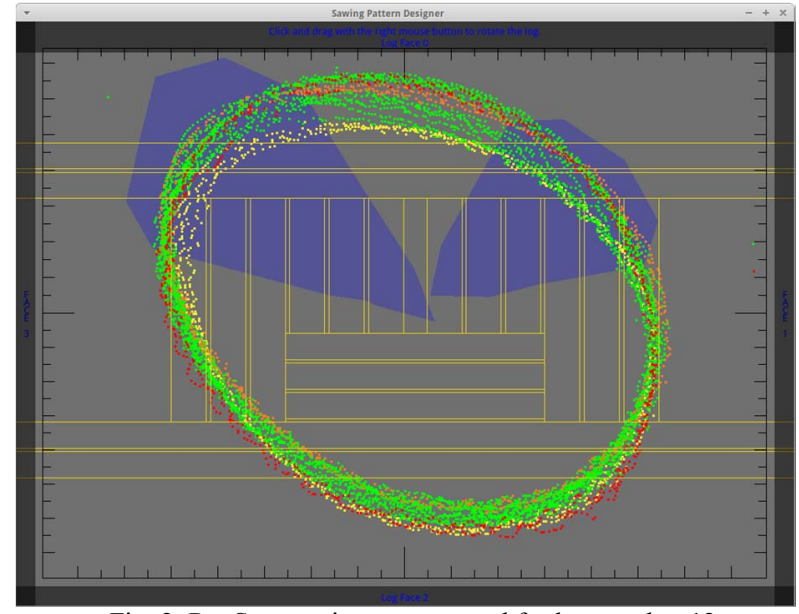

Fig. 2. RaySaw sawing pattern used for log number 12 .

\section{Timbers cut-up simulator}

Prior to defecting the timbers resulting from the sawing process using RaySaw [13], the thickness and width of the timbers were shrunk by the tangential shrinkage factor of $8.2 \%$ [18] to account for drying. Also, to produce usable material for the manufacture of CLT, the timbers, which are roughly edged (i.e., contain some wane) and contain defects not allowed for the manufacture of CLT, need to be defected. To remove the wane and the defects from the timbers to comply with manufacturing specifications [17], the ROMI simulator [14] was employed as ROMI is a well tested and widely used rough mill simulator [19]. ROMI processes rough random width and length timbers and produces dimensional parts, shown in blue, that meet user size and grade specifications (Figure 3). ROMI reports the number and volume of parts produced including the number of cutting operations required to achieve those results. Although ROMI can process parts using a rip-first, chop-first, or combined rip- and chopfirst operation, we employed a rip-first operation mode only. This processing method is more commonly used in real-world mills and offers greater mill throughput than do other processing methods.

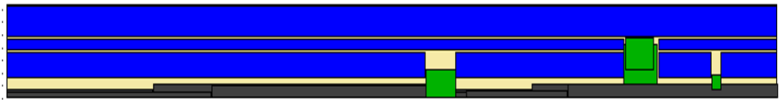

Fig. 3. ROMI cut-up pattern of one timber sawn by RaySaw. 
TABLE I

Dimensions, market value, volumes, and boards produced from the $22 \log$ sample.

\begin{tabular}{crrrrrrr}
\hline Log & $\begin{array}{c}\text { Diame- } \\
\text { ter }\end{array}$ & Length & $\begin{array}{c}\text { Market } \\
\text { value }\end{array}$ & $\begin{array}{c}\text { Whole } \\
\text { log } \\
\text { volume }\end{array}$ & $\begin{array}{c}\text { Sawn } \\
\text { green } \\
\text { volume }\end{array}$ & $\begin{array}{c}\text { Boards } \\
\text { pro- } \\
\text { duced }\end{array}$ & $\begin{array}{c}\text { Dried } \\
\text { planed } \\
\text { volume }\end{array}$ \\
\hline$\#$ & $(\mathrm{~mm})$ & $(\mathrm{m})$ & $(\mathrm{US} \$)$ & $\left(\mathrm{m}^{3}\right)$ & $\left(\mathrm{m}^{3}\right)$ & (units) & $\left(\mathrm{m}^{3}\right)$ \\
\hline 1 & 457 & 4.267 & 37.40 & 1.046 & 0.736 & 18 & 0.608 \\
2 & 330 & 3.658 & 14.60 & 0.490 & 0.305 & 12 & 0.271 \\
3 & 305 & 4.877 & 3.16 & 0.505 & 0.345 & 10 & 0.288 \\
4 & 356 & 4.877 & 22.80 & 0.679 & 0.489 & 14 & 0.416 \\
5 & 330 & 3.658 & 14.60 & 0.451 & 0.262 & 10 & 0.233 \\
6 & 356 & 3.048 & 14.40 & 0.472 & 0.297 & 13 & 0.266 \\
7 & 330 & 3.658 & 14.60 & 0.485 & 0.300 & 11 & 0.262 \\
9 & 279 & 3.658 & 2.00 & 0.374 & 0.223 & 10 & 0.192 \\
10 & 254 & 3.048 & 3.50 & 0.274 & 0.183 & 9 & 0.152 \\
11 & 483 & 4.267 & 21.00 & 1.146 & 0.833 & 19 & 0.691 \\
12 & 457 & 3.658 & 16.00 & 0.909 & 0.652 & 18 & 0.539 \\
13 & 305 & 3.658 & 5.90 & 0.378 & 0.255 & 10 & 0.216 \\
14 & 457 & 4.267 & 18.70 & 1.039 & 0.727 & 18 & 0.637 \\
15 & 406 & 3.048 & 9.90 & 0.652 & 0.270 & 9 & 0.227 \\
17 & 432 & 3.658 & 27.80 & 0.743 & 0.438 & 14 & 0.388 \\
18 & 432 & 4.877 & 37.00 & 1.030 & 0.685 & 16 & 0.568 \\
19 & 381 & 3.048 & 17.80 & 0.548 & 0.375 & 14 & 0.316 \\
20 & 356 & 3.658 & 3.44 & 0.550 & 0.364 & 13 & 0.298 \\
21 & 330 & 4.877 & 19.40 & 0.595 & 0.390 & 12 & 0.320 \\
22 & 279 & 3.048 & 4.50 & 0.337 & 0.154 & 9 & 0.128 \\
\hline Total & & & 308.50 & 12.702 & 8.282 & 259 & 7.015
\end{tabular}

\section{E. CLT production specifications}

To assure the quality and the safety of the product used for structures, standards have been established as to the material and the processes. Thus, the simulations conducted complied with CLT production requirements according to the European Standard FprEN 16351 [17] and to the American Standard ANSI/APA PRg 320-2012 [19]. In particular, the production of three-layered panels with edge-bonded timber layers was simulated, as it would not be economically realistic to extract wide enough material from the logs procured for three-layered panels with plain timber layers. For plain timber layers, the minimum lamination timber width for a $34 \mathrm{~mm}$ thick lamination is $136 \mathrm{~mm}$ [17]. For edge-bonded timber layers, the European standard does not specify a minimum lamination timber width, but the American standard [19] specifies a minimum timber width of 1.5 times the lamination thickness, or $51 \mathrm{~mm}$ for a 34-mm thick layer. Thus, we used $51 \mathrm{~mm}$ as the minimum acceptable timber width in the simulations. We simulated the production of finger-jointed timbers with $20-\mathrm{mm}$ long fingers. The minimum and maximum length of the timbers finger jointed was $200 \mathrm{~mm}$ and 5 meters, respectively.

To assure the structural integrity of the CLT panels produced, the standards describe timber characteristics that are known to weaken their strength, knots among them. The European standards ignore knots less than 6 $\mathrm{mm}$ in diameter, and exclude knots larger than $6 \mathrm{~mm}$ from a zone $20 \mathrm{~mm}$ plus 3 times the knot diameter from the end of the timber. Unfortunately, ROMI's [14] defect proximity rules control defect placement only along the lengthwise edges of the strip, not along the ends. Thus,
ROMI produced sound lamination timbers and allowed defects as large as $50 \mathrm{~cm}^{2}$ surface area on $90-\mathrm{mm}$ and wider timbers, and defects up to $15 \mathrm{~cm}^{2}$ on $51-\mathrm{mm}$ wide timbers. Because the ROMI simulation program is not able to handle defect proximity specifications at the end of lamination timbers, yield will be slightly overstated. In addition, when drying lumber, degrade (e.g., splits, checks, and warp) occurs, none of which was taken into account by our simulation, introducing another inaccuracy to our results.

\section{RESULTS}

U.S. hardwood sawmills typically cut logs such that the opening cut results in timber with a minimum width of $100 \mathrm{~mm}$ for Common grade timber, or $150 \mathrm{~mm}$ for Selects and Better grades, thereby following minimum width requirements stipulated in the NHLA rules for the measurement and inspection of hardwoods [20]. However, in this study, the sawing focused on maximizing the production of timber for the manufacture of CLT. Thus, more flexibility existed in the design of the sawing patterns than normally enjoyed by sawyers. By narrowing the opening face, we were able to reduce the amount of wood in the slabs (i.e., residues) and increase recovery on some logs.

\section{A. Production yields}

Table 1 lists the volumes (kiln dried planed volume) and the number of timbers (number of boards produced) obtained from each log from the simulation analysis using RaySaw [13]. Overall, 259 timbers (boards) totaling $7.02 \mathrm{~m}^{3}$ when dried and surfaced were sawn from $12.70 \mathrm{~m}^{3}$ of logs.

Table 2 presents the yield in CLT components from the timbers sawn from each log using the ROMI lumber rough mill simulation software [14]. Yield for individual timbers ranged from a low of $67.80 \%$ to a high of $89.21 \%$ with an overall average yield of $78.09 \%$. While higher yields may be achievable, it would result in excessive numbers of narrow and short parts, resulting in costly handling and glue-up for CLT panels. Thus, the simulation setting were such that a higher prioritization was given on wider and longer part sizes, thereby ensuring the production of larger lamination components, which do require less handling and are more economical to glue-up into CLT panels. 
TABLE 2

Yield and production overview for the timber simulations

\begin{tabular}{crrr}
\hline Log & Part count & $\begin{array}{c}\text { Primary } \\
\text { yield }\end{array}$ & $\begin{array}{c}\text { Primary } \\
\text { part volume }\end{array}$ \\
\hline$(\#)$ & & (percent) & $\left(\mathrm{m}^{3}\right)$ \\
\hline 1 & 53 & 82.31 & 0.510 \\
2 & 24 & 77.79 & 0.220 \\
3 & 51 & 73.74 & 0.222 \\
4 & 37 & 79.41 & 0.345 \\
5 & 43 & 76.93 & 0.187 \\
6 & 28 & 82.65 & 0.229 \\
7 & 30 & 79.33 & 0.217 \\
9 & 18 & 89.21 & 0.179 \\
10 & 33 & 76.30 & 0.121 \\
11 & 66 & 78.16 & 0.564 \\
12 & 92 & 67.80 & 0.382 \\
13 & 38 & 72.81 & 0.164 \\
14 & 72 & 80.25 & 0.534 \\
15 & 35 & 72.07 & 0.171 \\
17 & 40 & 77.93 & 0.316 \\
18 & 68 & 81.25 & 0.482 \\
19 & 47 & 78.44 & 0.259 \\
20 & 64 & 75.70 & 0.236 \\
21 & 26 & 74.29 & 0.248 \\
22 & 26 & 85.51 & 0.114 \\
\hline Total & 891 & 78.09 & 5.702
\end{tabular}

Table 3 shows the total length of components obtained from each $\log$ by width. Wider lamination components require fewer glue-joints and minimize material handling and labor costs as opposed to narrower components. A total of 1,716 lineal meters of 51,90 , 110,130 , or $150 \mathrm{~mm}$ width was produced with the largest percentage accumulating in the narrowest width. In fact, 33\% (572 lineal $\mathrm{m}$ ) of all components were 51 $\mathrm{mm}$ wide, with $12 \%$ (214 lineal $\mathrm{m}$ ), $25 \%$ (424 lineal $\mathrm{m}$ ), $12 \%$ (200 lineal $\mathrm{m}$ ), and 18\% (307 lineal $\mathrm{m}$ ) accruing in $90,110,130$, and $150 \mathrm{~mm}$ widths, respectively (Table 3 ).

\section{DISCUSSION}

Experience and preliminary experiments using the RaySaw [13] and the ROMI [14] simulation software indicate that CLT lamination components of $200 \mathrm{~mm}$ and wider can be obtained from the resource, somewhat wider than the component widths investigated in this study. However, doubts exist that lamination timbers this wide would be suitable for CLT production since such wide timbers are prone to cupping and bowing during the drying process, resulting in high degrees of crook or sweep, making the timbers unusable. Thus, production of $200 \mathrm{~mm}$ and wider lamination components will likely result in low production yield after drying and will, most likely, not be economical from a cost standpoint. Also, timbers wide enough to cut such large lamination components are typically the higher grade [20] higher value output of the sawing process that commands premium prices in the market for appearance grade lumber. It is, thus, unlikely to be economically feasible to use such timbers for the manufacture of CLT panels.
TABLE 3

Lamination timber width production overview (lineal count)

\begin{tabular}{crrrrr}
\hline \multicolumn{7}{c}{ Lineal count (m) by strip width (mm) } \\
Log & \multicolumn{1}{c}{51} & \multicolumn{1}{c}{90} & \multicolumn{1}{c}{110} & \multicolumn{1}{c}{130} & \multicolumn{1}{c}{150} \\
\hline$\#$ & \multicolumn{1}{c}{$(\mathrm{m})$} & \multicolumn{1}{c}{$(\mathrm{m})$} & \multicolumn{1}{c}{$(\mathrm{m})$} & $(\mathrm{m})$ \\
\hline 1 & 48.40 & 9.33 & 41.12 & 3.81 & 48.13 \\
2 & 9.11 & 8.78 & 7.74 & 28.16 & 3.96 \\
3 & 27.34 & 12.68 & 17.92 & 4.63 & 9.42 \\
4 & 22.22 & 5.15 & 14.90 & 39.35 & 10.12 \\
5 & 32.03 & 3.32 & 24.41 & 2.77 & 3.47 \\
6 & 19.87 & 6.92 & 15.27 & 2.29 & 20.09 \\
7 & 17.74 & 4.24 & 17.16 & 7.56 & 14.14 \\
9 & 14.36 & 0.21 & 13.08 & 5.55 & 14.78 \\
10 & 6.77 & 7.22 & 5.82 & 3.14 & 9.20 \\
11 & 63.28 & 28.96 & 30.78 & 6.89 & 43.83 \\
12 & 57.24 & 13.35 & 42.52 & 4.27 & 13.84 \\
13 & 6.22 & 9.63 & 14.75 & 3.75 & 15.51 \\
14 & 54.28 & 24.96 & 42.28 & 13.50 & 26.91 \\
15 & 19.99 & 9.27 & 6.95 & 12.10 & 5.82 \\
17 & 29.08 & 10.73 & 26.09 & 3.93 & 20.85 \\
18 & 75.56 & 11.31 & 57.33 & 3.63 & 16.92 \\
19 & 7.80 & 7.19 & 25.02 & 1.77 & 15.82 \\
20 & 32.06 & 24.41 & 3.63 & 13.84 & 6.19 \\
21 & 20.54 & 7.07 & 11.49 & 30.48 & 4.85 \\
22 & 7.59 & 9.02 & 5.24 & 8.47 & 2.96 \\
\hline Total & 571.50 & 213.76 & 423.52 & 199.89 & 306.81
\end{tabular}

However, this research has shown that a relatively high yield of narrower laminate timbers can be recovered from yellow-poplar logs typically sawn in US hardwood sawmills. With sawmill yields of $65 \%$ on average of the 22 logs sawn and rough mill yields of $78 \%$ for a total yield of approximately $50 \%$, this study has shown that relatively high yield when sawing timbers for CLT can be achieved. Yet, this research has also uncovered the need to enhance the capabilities of the ROMI software to account for the location of knots at the ends of components. Also, additional research is needed to better understand the relationship between the type and size of allowable characteristics in the lamination timbers and yield as well as the influence of these characteristics on the mechanical properties of the resulting panels. Furthermore, software is needed to better simulate the drying of timbers, enabling this research to better estimate drying rejects and volumetric shrinkage.

\section{SUMMARY AND CONCLUSIONS}

CLT, an environmentally friendly building material with numerous benefits, is mostly made using softwoods. However, the material has gained interest within the US hardwood industry as a potential market. Special attention is being paid to yellow-poplar CLT panels, as yellow-poplar is a strong yet rather light material, which is well suited for certain building applications. This study investigated the yield of yellow-poplar logs for the manufacture of CLT panels.

Using the RaySaw sawing and the ROMI rough mill simulator and a digital databank of laser-scanned yellowpoplar logs, the yield-recovery potential for timbers used in the production of CLT was investigated. The simulated sawing and cut-up of 22 low-grade yellowpoplar logs resulted in yields of $65 \%$ and $78 \%$ for the log 
sawing and the timbers cut-up, respectively, for an overall yield of $50 \%$. The result from this study confirms the feasibility of manufacturing CLT from yellow poplar logs and provides a base-line for the assessment of the impact that the increased use of hardwood CLT would have on our forest resource.

However, as the simulation software used was not able to cut all the components exactly according to the standards with respect to the location of certain characteristics, the yield information found in this study my change slightly once the software has been adapted. Further research is also needed into the relationship between the acceptance of characters and their size in lamination timbers with respect to yield improvements and to the mechanical properties of resulting panels.

\section{REFERENCES}

[1] Crespell, P. and S. Gagnon. 2011. Cross-Laminated Timber: a Primer. FPInnovations: Vancouver, B.C. Canada.

[2] reThink Wood. 2014. Tall wood takes a stand. [cited Nov. 18, 2014]; Available from: www.rethinkwood.com/sites/default/files/Tall Wood C EU Nov 2014.pdf

[3] WoodWorks. 2012. Solid advantages. [cited Nov. 18, 2014]; Available from: www.woodworks.org/wp content/uploads/IS CLT.pdf

[4] Karacabeyli, E. and B. Douglas. 2013. Cross-Laminated Timber Handbook. ed. E. Karacabeyli and B. Douglas. FPInnovations and Binational Softwood Lumber Council: Pointe-Claire, QC. 572 p.

[5] Espinoza, O., V. R. Trujillo, M. F. Laguarda-Mallo, and U. Buehlmann. 2015. Cross-laminated timber: status and research needs in Europe. BioResources, 11(1), 281-295.

[6] European Standards. 2004. CSN EN 1995-1-1 Eurocode 5: Design of timber structures - Part 1-1: General - Common rules and rules for buildings. [cited Jan. 6, 2017]; Available from: https://www.en-standard.eu/csn-en-19951-1-eurocode-5-design-of-timber-structures-part-1-1general-common-rules-and-rules-for-buildings/

[7] AHEC. 2017a. Why Tulipwood CLT? [cited Jan. 6, 2017]; Available at: http://www.americanhardwood.org/

[8] Hovanec, D. 2015. Effect of Wood Characteristics on Adhesive Bond Quality of Yellow Poplar for Use in Cross Laminated Timbers. West Virginia University, Morgantown, WV.

[9] Mohamadzadeh, M., and D. Hindman. 2015. Mechanical Performance of Yellow Poplar Cross Laminated Timber. Report No. CE/VPI ST 15 13. Virginia Tech, Blacksburg, VA.

[10] Kramer, A., A. Barbosa, and A. Sinha. 2014. Viability of Hybrid Poplar in ANSI Approved Cross Laminated Timber Applications. Journal of Materials in Civil Engineering, 26(7):3.

[11] Banks, J. 1998. Principles of simulation. Chapter 1 In: Handbook of Simulation. Edited by J. Banks. Wiley. New York, NY. Pp. 3-30.

[12] Thomas, R. E., L. H. Thomas, and C. A. Shaffer. 2008. Defect detection on hardwood logs using high-resolution laser scan data. In: Proceedings of the 15th international symposium on nondestructive testing of wood; 2007 September 10-12; Duluth, MN: Natural Resources
Research Institute, University of Minnesota Duluth: 163167.

[13] Thomas, R. E. 2013. RAYSAW: a log sawing simulator for 3D laser-scanned hardwood logs. In: G. Miller, T. M. Schuler, K. W. Gottschalk, J. R. Brooks, S. T. Grushecky, B. D. Spong, J. S. Rentch, eds. Proceedings, 18th Central Hardwood Forest Conference; 2012 March 26-28; Morgantown, WV; Gen. Tech. Rep. NRS-P-117. Newtown Square, PA: USDA, Forest Service, Northern Research Station: 325-334.

[14] Thomas, R. E., T. Grueneberg, and U. Buehlmann. 2015. ROMI 4.0: Rough mill simulator 4.0 users manual. Gen. Tech. Rep. NRS-143. Newtown Square, PA: U.S. Department of Agriculture, Forest Service, Northern Research Station. $82 \mathrm{p}$.

[15] Rast, E. D., D. L. Sonderman, G. L. Gammon. 1973. A Guide to Hardwood Log Grading. Gen. Tech. Rep. NE-1. Upper Darby, PA: USDA, Forest Service, Northeastern Forest Experiment Station. $32 \mathrm{p}$.

[16] Thomas, R. E. 2009. Modeling the relationships among internal defect features and external Appalachian hardwood log defect indicators. Silva Fennica. 43(3): 447456.

[17] European Committee for Standardization. 2015. European Standard: Timber structures - Cross laminated timber Requirements. Ref. No. FprEN 16351:2015E. CENCENELEC Management Centre, Brussels. 101p.

[18] Forest Products Laboratory. 1999. Wood handbook Wood as an engineering material. Gen. Tech. Rep. FPLGTR-113. Madison, WI: USDA, Forest Service, Forest Products Laboratory. $463 \mathrm{p}$.

[19] Thomas, E. R. and U. Buehlmann. (2002). Validation of the ROMI-RIP rough mill simulator. Forest Products Journal, 52(2):23-29.

[20] ANSI / APA 2012. Standard for Performance-Rated Cross-Laminated Timber. ANSI/APA PRG 320-2012. American National Standards Institute (ANSI) and American Plywood Association (APA). The Engineered Wood Association, Tacoma, WA. 23p.

[21] National Hardwood Lumber Association (NHLA). 2011. Rules for the measurement \& inspection of hardwood \& cypress plus NHLA sales code \& inspection regulations - $\mathrm{v} 1.1$. http://www.nhla.com/assets/1603/2011_rules_book.pdf. Accessed January 27, 2014. 